\title{
Turismo rural e agricultura familiar: o caso de Nossa Senhora do Livramento-MT
} Agricultural tourism and familiar agriculture: the case of Nossa Senhora do Livramento-MT Tourisme agricole et agriculture familière: le cas de Nossa Senhora do Livramento-MT Turismo rustico y agricultura familiar: el caso el Nossa Senhora do Livramento-MT

\author{
Carlos Alberto Simões de Arruda* \\ Silvia Regina Fernandes Vilanova* \\ José Franklim Chichorro***
}

Recebido em 12/10/2007; revisado e aprovado em 23/11/2007; aceito em 13/6/2008.

\begin{abstract}
Resumo: Este artigo discute o turismo rural e a agricultura familiar como possibilidades do desenvolvimento local em Nossa Senhora do Livramento - MT sugere usar de maneira eficiente e de formas alternativa os recursos ambientais existentes através da agricultura orgânica, do artesanato, agregando valores a produtos naturais e a produção existente e organizar o setor. No trabalho foi identificado pouco intercambio de informação entre as duas estratégias, fator que com certeza demonstra as reais necessidades de estudo e planejamento que possa aportar e melhor desenvolver o rural distribuindo renda e qualidade de vida das pessoas que ali residem e exercem influência direta na racionalidade do uso dos recursos ambientais. Palavras-chave : Desenvolvimento local. Ruralidade. Folclore.
\end{abstract}

Abstract: This article discusses rural tourism and agriculture as a family that can give a local development in Nossa Senhora do Livramento - MT suggests using efficient ways and alternative forms of the environmental resources through the existent organic farming, handicrafts, adding value to natural products and production existing and organize the industry. At this work has been identified little exchange of information between the two strategies as a factor that will certainly demonstrates the real needs of the study and the planning that can provide better and develop the rural distributing income and quality of live of people who live and have influence rationality on the use of environmental resources.

Key words: Local development. Rurality. Folklore.

Résumé: Cet article discute le tourisme agricole et l'agriculture familière je mange des possibilités du développement local dans Nossa Senhora do Livramento - MT suggère d'utiliser de manière efficace et de formes alternatives les ressources environnementales existantes à travers l'agriculture organique, de l'artisanat, en s'ajoutant valeurs à des produits naturels et la production existante et d'organiser le secteur. Dans le travail il a été identifié peu d'échange d'informations entre les deux stratégies, facteur qui avec certitude démontre les réelles nécessités d'étude et planification qui puisse accoster et meilleur il développera l'agricole en distribuant revenu et qualité de vie des personnes qui là habitent et exercent influence directe dans la rationalité de l'utilisation des ressources environnementales.

Mots-clé: Développement local. Ruralité. Folklore.

Resumen: Este artículo charla por el turismo rústico \& el agricultura familiar como posibilidad de la desenvolvimiento sitio em Nossa Senhora do Livramento - MT sugerir uso de manera todo - a la vuelta de \& de formas alternación el recurso medioambiental existente vía el agricultura orgánico, de la artesanía, agregado valores el productos nativos \& el producción existente \& organizar el área. Estar trabajando estado identificable pequeño intercambio de información entre el dos estratégico , factor como con el certeza ella manifestar el realidad necesidades de estudio \& planificando qué poseer afijo \& mejor revelar el rústico repartiendo ingreso \& cualidad de vida del gente qué entonces residir \& ejercicio influencia horrendo en racionalidade de la uso del recursos ambientales.

Palabras clave : Desenvolvimiento local. Ruralidade. Folklore.

\section{Introdução}

O turismo e a agricultura familiar são atividades importantes para a gestão dos recursos ambientais onde contribuem positivamente ou não. Sendo assim terão influencia direta na dinâmica ambiental. O tu- rismo passou a ter importância em todos os setores pelos aspectos sociais, econômicos, culturais e políticos. A globalização traz possibilidades que a pouco tempo não seriam sequer imaginadas.

Segundo o documento, do Ministério do Turismo, "Diretrizes para o Desenvolvimento

*Mestrando do Programa de Pós-Graduação em Ciências Florestais da Universidade Federal de Mato Grosso. Endereço: Travessa Ipiranga, 120, Bairro da Manga, CEP 78115-550. Várzea Grande-MT. E-mail: arrudacarlos33@yahoo.com.br.

**Mestranda do Programa de Pós-Graduação em Ciências Florestais da Universidade Federal de Mato Grosso. Endereço. Rua General Zenóbio da Costa, 112, Bairro Duque de Caxias, CEP 78043-374. Cuiabá-MT. E-mail: vilanova.silvia@gmail.com.

***Coordenador do Programa de Pós-Graduação em Ciências Florestais da Universidade Federal do Espírito Santo. E-mail: jfranklim@terra.com.br. 
do Turismo Rural", a conceituação de Turismo Rural fundamenta-se em aspectos que se referem ao turismo, ao território, à base econômica, aos recursos naturais e culturais e à sociedade. Com base nesses aspectos, e nas contribuições dos parceiros de todo o País, define-se Turismo Rural como:

o conjunto de atividades turísticas desenvolvidas no meio rural, comprometido com a produção agropecuária, agregando valor a produtos e serviços, resgatando e promovendo o patrimônio cultural e natural da comunidade. (BRASIL, 2007)

Segundo Abramovay (2003, p. 33), "Por um lado, pela oposição aos transtornos e a insegurança da vida urbana e metropolitana, um dos fatores que produzem mundialmente um movimento migratório, inclusive de camadas de média e alta renda e com boa formação educacional, para áreas não densamente povoadas. Por outro lado, nas áreas não densamente povoadas é, com freqüência, menor o sentimento de solidão trazido pelo anonimato da vida metropolitana: sobretudo quando essas áreas podem representar a recuperação e o esforço de relações de proximidade familiar, comunitária e de vizinhança. Que estes valores possam transformar-se em fontes de desenvolvimento e geração de renda vai depender tanto da organização dos habitantes e das instituições rurais, como sobretudo, do tipo de relação que conseguem estabelecer com as cidades.

Turismo como desenvolvimento local para ser instrumento de promoção de melhoria de qualidade de vida deve obrigatoriamente fazer parte da vontade e das atitudes da comunidade, neste caso entendese, moradores locais, freqüentadores eventuais, comercio, indústria, produtores, ongs, universidades, escolas, governos e todos com ações diretas nesta comunidade.

No Brasil, assim como no mundo, o setor de hospedagem é constituído em sua maioria de pequenos e médios estabelecimentos, principalmente quando se fala de turismo sustentável ou vinculado ao "Ambiente Natural". Por toda a potencialidade de ecossistemas, fauna, flora, e variedade socioeconômica, o debate sobre o desenvolvimento do Ecoturismo no Brasil vem buscando caminhos para maior conscientização e compromisso de parte do setor privado com pos- turas responsáveis, capazes de contribuir à sustentabilidade ambiental, econômica e social do setor.

Aulicino (1997), conclui em seu trabalho intitulado, "Algumas implicações da exploração turística dos recursos naturais", dizendo: "A exploração turística dos recursos ambientais deve revelar que em primeiro lugar se está prestando um serviço cujo objetivo final é, sem duvida, o lucro: mas lucro como retorno da qualidade de um serviço prestado que deve ser cuidadoso com o turista e com o ambiente que inclui necessariamente a comunidade humana local".

Abramovay (1992) faz uma contribuição importante ao analisar o surgimento do agricultor familiar moderno, recuperando o que seria seu caráter distintivo em relação ao camponês. Para o autor, o produtor familiar na sociedade moderna representa uma forma de produção

altamente integrada com o mercado, capaz de incorporar os principais avanços técnicos e de responder às políticas governamentais [...] Aquilo que era antes de tudo um modo de vida, converteu-se numa profissão, numa forma de trabalho. (ABRAMOVAY, 1992, p. 22)

Segundo ele, o que era uma categoria social fadada à decomposição no processo de expansão do capitalismo nos clássicos marxistas converteu-se no seu expoente mais saliente. Outros autores abordam de outra forma a reprodução da agricultura familiar no capitalismo, como é o caso de Mann e Dickinson (1978), que atentam para a dificuldade no surgimento das empresas capitalistas na agricultura, uma vez que há uma nítida separação entre tempo de trabalho e tempo de produção na agricultura. Esta separação acabou inspirando Aidar e Perosa Júnior (1981) a afirmarem que as unidades familiares modernas de produção são parceiras privilegiadas do capital agroindustrial.

Como os principais impactos econômicos temos a sobrevalorização de terras e imóveis, da pressão para que a exploração seja alem da capacidade de suporte e ainda o aumento do custo de vida na região; Os Benefícios econômicos que podem ser observados a curto e médio prazo, é a criação de empregos formais e a melhor distribuição de renda. 
Como impacto ambiental propriamente dito pode ocorrer alteração da paisagem, poluição dos mananciais, do solo, sonora e do ar; captura de animais e retirada de espécies silvestres. Alterações comportamental e hábitos alimentares da biota. Os benefícios ambientais devem ocorrer na conservação de áreas naturais, conscientização sobre o equilíbrio do meio ambiente, controle dos agentes poluidores, e principalmente a manutenção da paisagem.

Os impactos sociais que ocasionalmente acontecem são os conflitos entre a comunidade e atores externos, a perda dos valores culturais locais, tradições, crenças, artesanato e outros.

Espera-se como beneficio social, os investimentos na infra-estrutura viária, de comunicação, de abastecimento, saúde publica e sanitários dando respaldo as atividades do turismo local, e ainda fortalece o artesanato, comercio local, às manifestações culturais e tradições.

Del Grossi (1999) observou que a população rural do Brasil, não é exclusivamente agrícola, uma vez que mais de 3,9 milhões de pessoas estava ocupado em atividades não-agrícolas, em 1995, o que representava $26 \%$ da PEA - População Economicamente Ativa, rural ocupada. Segundo este autor, a PEA rural não-agrícola, de certa forma, vem mantendo o contingente de trabalhadores rurais, pois, enquanto os ocupados na agricultura permaneceram estagnados entre 1981 e 1995, a PEA rural não-agrícola aumentou em quase 1 milhão de pessoas em todo o país, principalmente nas regiões $\mathrm{Su}-$ deste e Centro-Oeste.

Considera-se o "Ecoturismo" como a atividade de junção das atividades de turismo rural e agricultura familiar no desenvolvimento local, mitigando os impactos ambientais dessas duas atividades, como alternativa concreta de geração de emprego e renda. A ruralidade é o ponto fundamental para atrair o turista para áreas rurais em assentamentos e comunidades tradicionais.

\section{2 Área de estudo, Nossa Senhora do Livramento - Mato Grosso.}

\subsection{Histórico e Antecedentes Legais}

O Município de Nossa Senhora do Livramento tem origens garimpeiras. Em 1730, paulistas sorocabanos descobriram ouro no Ribeirão dos Cocais, a 06 léguas de Cuiabá.

A crendice popular de Livramento conta que, durante uma viagem, ainda no começo do século XIX, a imagem de Nossa Senhora do Livramento passava pelo povoado de São José dos Cocais, vinda de Portugal carregada em cima do lombo de um burro. A comitiva parou para descansar e na saída o animal que carrega a imagem da Santa empacou. Não queria sair mais do lugar. Com isso, os chefes da comitiva decidiram desistir de ir adiante e construíram um pequeno rancho, no qual eternizaram a imagem de Nossa Senhora do Livramento. A partir daí, a santa emprestou seu nome à localidade.

O município foi criado pela Lei Provincial n. 598, de 19 de 1883. Em 31 de dezembro de 1943, houve alteração na denominação, passando para São José do Cocais. Tratava-se de retomar o primeiro nome da localidade. A Lei n. 179, de 30 de outubro de 1948, alterou o nome de São José dos Cocais para Nossa Senhora do Livramento, voltando à antiga denominação. $\mathrm{O}$ primeiro nome popular foi Cocais, depois São José dos Cocais, em referência ao rio e ao Santo protetor. A Lei n. 11, de 26 de agosto de 1835, criou a Paróquia de Nossa Senhora do Livramento, alterando assim, o nome original de São José dos Cocais (Seplan, 2004).

O Município a diversificação de culturas agrícolas e aproveitando as pastagens nativas permitiram um gradativo desenvolvimento da criação bovina para corte e produção de leite. Pela ocupação esparsa por conta dos "focos" de ouro, possui diversas comunidades que vivem cada uma com suas características próprias, povo trabalhador adaptado às adversidades do ambiente. Para subsistência tiveram que criar sistemas de produção próprios que passam de pai para filho, aproveitando as áreas mais férteis e apropriadas para cultivo. Trabalham preferencialmente em áreas de solos mais férteis 
e profundos, geralmente próximo a um córrego que normalmente é intermitente.

Famosa pela tradição de produção da Banana e seus derivados, também se destacam a cultura da mandioca para consumo in natura e produção de farinha, cana de açúcar e da rapadura, a pecuária e carne seca. A agricultura familiar tem se transformado em uma alternativa de melhoria da qualidade de vida as populações tradicionais bem como dos assentamentos hoje existentes.

Com Atrativos Turísticos o município ressalta a Igreja de Nossa Senhora do Livramento ícone da religiosidade do livramentense e região, construída no século XVIII e reformada em 1883. A obra que tem como cenário - a Praça da Bandeira, na Avenida Coronel Botelho, o templo chama atenção pelo seu modelo arquitetônico neoclássico.

O Relógio da Praça localizado na Praça Central foi idealizado pelo saudoso Frei Salvador Rouquette, vigário da Igreja local. No passado, a obra funcionava como antigo sistema de abastecimento de água da população, hoje, desativado. O relógio na torre da fonte ainda funciona pontualmente na praça principal da cidade. $\mathrm{O}$ Big-Bem dos papa-bananas, como são conhecidos os livramentense, construído na década de 30 é parte integrante do harmônico conjunto arquitetônico do município.

A Casa de São Benedito, sede oficial da festa do Santo, o local também é considerado a "casa" do Santo negro. Abriga as tradições Afro do município, ponto turístico que deve ser visitado por quem quer conhecer a historia viva do Brasil.

Na Comunidade de Mata-Cavalo, próximo a sede do município é possível conhecer famílias remanescentes de quilombolas. Neste espaço é possíveis entrar em contato com a história dos negros mato-grossenses, com sotaque próprio e único, artesanato, danças, músicas, cantigas, produção orgânica e ainda bela paisagens cênicas naturais e fazendas centenárias que datam da época dos escravos.

O folclore livramentense faz parte dos folguedos mais populares e antigos do Estado de Mato Grosso, é praticado principalmente na zona rural, fazendo parte da maioria das festas como casamento, batizados, carnaval, aniversário, etc., bem como festas como das tradicionais realizadas em louvor aos santos católicos.

Nossa Senhora do Livramento poder ser considerada como o berço da cultura mato-grossense, pois aqui ainda cultua-se a maioria das manifestações folclóricas do estado, como o Cururu, Siriri, Boi á Serra, Dança de São Gonçalo, Dança do congo e o autêntico rasqueado.

A Dança do Congo é uma das mais antigas representa a luta dos cristãos contra os mouros, tem forte influência africana, com devoção a São Benedito e N. Sra. do Rosário, pela liberdade concedida aos negros nas varias lutas apreendidas. O Siriri é um dos folguedos mais populares, pode-se dizer que é baile ou até mesmo o carnaval do povo. A Dança de São Gonçalo, e o Boi à Serra também são apresentados em festas e eventos, mostrando a variedade folclórica livramentense.

\subsection{Informações do Município}

- Relevo - Depressão rio Paraguai, calha do rio Cuiabá. Participa do pantanal de Mato Grosso, Serras das Araras.

- Distância da Capital - $32 \mathrm{Km}$.

- Formação Geológica - Coberturas dobradas do Proterozóico, com granitóides associados, Grupo Alto Paraguai e Cuiabá. Faixa Móvel Brasiliana.

- Bacia Hidrográfica - Grande Bacia do Prata. Para esta bacia contribuem as bacias dos rios Paraguai e Cuiabá. O Paraguai recebe, pela esquerda, os rios Jauguara e Sangradouro Grande. O rio Cuiabá faz divisa, a leste com o município de Barão de Melgaço.

- Economia - Destaca-se a pecuária, no sistema de cria, recria e corte. A agricultura é de subsistência, destaque para a produção de bananas. O extrativismo mineral é largamente praticado no município, que possui imensas jazidas auríferas. PIB $\underline{\mathrm{R} \$}$ 44.848.964,00 IBGE / 2003, PIB per capita $\underline{\mathrm{R} \$ 3.503,55 \text { IBGE / } 2003 .}$

- Altitude na sede 232 metros.

- Clima - Tropical quente e sub-úmido, com 5 meses de seca, de maio a setembro. Precipitação anual de $1.750 \mathrm{~mm}$, com intensidade máxima em dezembro, janeiro e fevereiro. Temperatura média anual: $24^{\circ}$ 
$\mathrm{C}$, maior máxima $42^{\circ} \mathrm{C}$, e menor $0^{\circ} \mathrm{C}$. $\mathrm{O}$ clima da região de Cuiabá é do tipo Aw de Köppen, ou seja, tropical semi-úmido com temperatura média de $24^{\circ}$ a $26^{\circ} \mathrm{C}$, com quatro a cinco meses secos e duas estações bem definidas: uma seca (outono-inverno) e uma chuvosa (primavera-verão), com índice pluviométrico médio anual de 1250 a $1500 \mathrm{~mm}$ (MAITELLI, 1994).

- A População Total do Município era de 12.141 de habitantes, de acordo com o Censo Demográfico do IBGE (2000).

- Área é de $5.192,57 \mathrm{~km}^{2}$ representando 0.5748 \% do Estado, $0.3244 \%$ da Região e $0.0611 \%$ de todo o território brasileiro.

- O Índice de Desenvolvimento Humano (IDH) é de 0.655 / PNUD (2000).

- Altitude da Sede: $232 \mathrm{~m}$

- O Município foi premiado com atrativos Naturais como Serra das Araras, localizada cerca de $120 \mathrm{~km}$ da sede, a área que possui 71.462.64 hectares foi transformada em APA - Área de Proteção Ambiental. Possui uma diversidade abundante de recursos hídricos, com minas de água e complexo com mais de 20 cachoeiras já conhecidas. Entre as cachoeiras mapeadas estão, Cachoeira das Araras, o complexo Bacaina, localizada na Serra das Araras, na região médio Pantanal do município, é formada pelas cachoeiras de Borbô, do Tembé, do Boni e do Estrela.

\section{Hidrografia}

A hidrografia do Município é composta principalmente dos Rios Bento Gomes, Cuiabá, Espinheiro, Formigueiro, Pari, Piraim, Sangradouro e Santana ; Córregos Landi, e Corvo e do Ribeirão dos Cocaes. Ainda possui diversos córregos menores.

\section{Vegetação}

A cobertura vegetal do Município é do tipo semicaducifólia, apresentando três situações distintas: árvores de grande porte, árvores de porte médio e um mais ralo arbustivo nos terrenos mais elevados.

\section{Étnico}

A mistura das raças branca e negra não ocorreu com intensidade, permanecendo as duas de modo mais puro que em outras regiões. Por esse costume, a sociedade apresenta características múltiplas, qualidades, defeitos, modismos de linguajar nitidamente locais, diferentes de outras comunidades regionais e locais.

\section{Metodologia}

\subsection{Características da unidade de estudo}

As comunidades rurais do município de Nossa Senhora do Livramento, Mato Grosso, tiveram suas origens no garimpo de ouro. A exemplo do que ocorre em outros garimpos do Estado, devido ao sistema de extração ser do tipo "modo de cata", as lavras foram se esgotando de modo que a vida se restringiu à agricultura de subsistência (Ferreira, 2001).

A diversificação de culturas agrícolas e o aproveitando das pastagens nativas permitiram um gradativo desenvolvimento da criação bovina para corte e produção de leite. Por conta dos "focos" de ouro e pela ocupação esparsa se estabeleceram diversas comunidades, cada uma com suas características próprias, com trabalhadores adaptados às adversidades do ambiente.

Essas comunidades são conhecidas pela tradição de produção da banana e seus derivados. Destacam-se, também, pelo cultivo da mandioca para consumo in natura e para a produção de farinha; a cana-de-açúcar muito usada para a produção da rapadura; e a pecuária de leite e de corte, com produção de carne-seca. A agricultura familiar tem se transformado em uma alternativa de melhoria da qualidade de vida dos moradores (SEPLAN, 2004).

\subsection{Coleta e Análise de dados}

Segundo Lüdkee André (1986), a pesquisa que tem o intuito de abordar e analisar as opiniões do público alvo, dentre outras características, é classificada como pesquisa qualitativa. Foram levantados fatores em âmbito social, cultural e relacionados à questão ambiental. 
A percepção ambiental dos entrevistados em relação aos recursos naturais foi avaliada pela escala de adição de Likert (1932). Esse método baseia-se na premissa de que a atitude geral dos indivíduos se remete às crenças sobre o objeto da atitude, à força que mantém essas crenças e aos valores ligados ao objeto (Oliveira, 2001). Por meio do questionário os entrevistados não apenas respondem se consideram importantes ou não os itens questionados, mas também informam qual seu grau de importância (Silva, 2001).

O questionário foi composto por questões sobre as características sócio-econômicas dos entrevistados e 15 atributos, e foram aplicados em entrevistas pessoais e individuais à 56 moradores sendo visitadas 19 propriedades conforme figura 1 .

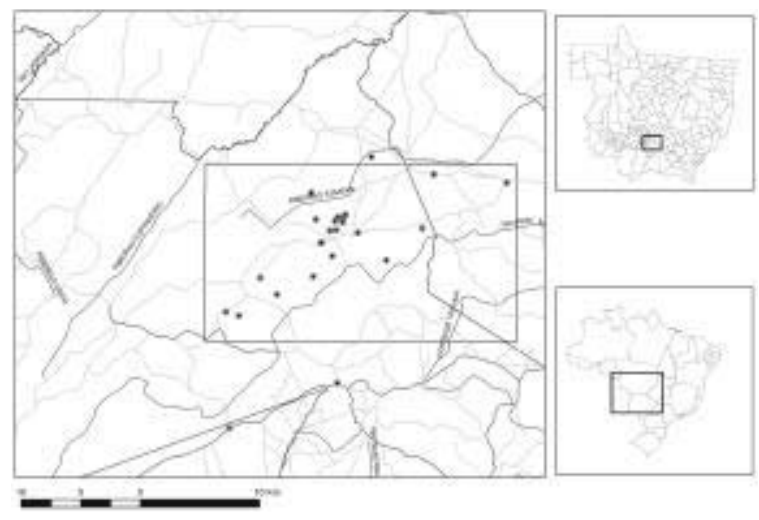

Figura 1. Mapa de localização das propriedades visitadas.

As questões visam avaliar a percepção da importância que os produtores rurais e familiares atribuem aos recursos naturais e se há ou não interesse em sua conservação. Cada item foi classificado por cada um dos entrevistados em uma escala de cinco pontos: 1. Não é Importante, 2. Pouco importante, 3. Tanto faz, 4. Importante, e 5. Essencial.

\section{Resultados e Discussão}

Observa-se que a comunidade possui pouca escolaridade sendo composto por $58,35 \%$ com $1^{\circ}$ grau incompleto e $36,6 \%$ não são escolarizados.

Com relação à faixa etária dos entrevistados $33,33 \%$ possuem entre 30 e 39 anos, entre 40 e 49 anos $27,78 \%$, e as faixas de 50 à 59 anos, 20 à 29 anos e mais de 60 anos $11,11 \%$ cada. Sendo que $55,56 \%$ são do sexo feminino e $44,44 \%$ do sexo masculino.

A renda média familiar dos entrevistados é constituída por: $45,5 \%$ de 1 à 3 salários mínimos, $45,5 \%$ de 3 à 5 salários, $18,2 \%$ abaixo de 1 salário mínimo e 3,85\% de 1 salário mínimo. Entre os entrevistados 16,07\% declararam trabalhar em outras propriedades.

A tabela 1 apresenta o resultado do questionário aplicado com os 15 atributos ambientais relacionados em ordem de importância atribuída pelos entrevistados.

Tabela 1.ordem de importância dos atributos ambientais para os pequenos agricultores de Nossa Senhora do Livramento-MT, 2007.

\begin{tabular}{cc}
\hline Colocação & Atributo \\
\hline $1^{\circ}$ & Recursos Hídricos \\
$2^{\circ}$ & Energia \\
$3^{\circ}$ & Diversidade vegetal \\
$4^{\circ}$ & Recursos Vegetais \\
$5^{\circ}$ & Aproveitamento \\
$6^{\circ}$ & Utilização \\
$7^{\circ}$ & Recursos Minerais \\
$8^{\text {ao }}$ & Diversidade animal \\
$9^{\circ}$ & Recursos Faunísticos \\
$10^{\circ}$ & Recursos Turísticos \\
$11^{\circ}$ & Conservação \\
$12^{\circ}$ & Preservação \\
$13^{\circ}$ & Reutilização \\
$14^{\circ}$ & Reciclagem \\
$15^{\circ}$ & Cultura Regional
\end{tabular}

\section{Agricultura familiar}

A agricultura familiar consiste em um modelo de produção onde a gestão produtiva tem como o núcleo de decisões, a gerência, o trabalho e o capital, na unidade familiar.

No Brasil segundo o IBGE - Censo agropecuário 1995/1996, existe 4.859.864 de estabelecimentos, os agricultores familiares representam $85,2 \%$ do total, ocupam 30,5\% da área total e são responsáveis por 37,9\% do Valor Bruto da Produção Agropecuária Nacional, recebendo apenas $25,3 \%$ do financiamento destinado a agricultura. O CentroOeste apresenta o menor percentual de agri- 
cultores familiares entre as regiões brasileiras, representando $66,8 \%$ dos estabelecimentos da região e ocupando apenas $12,6 \%$ da área regional e $12,7 \%$ dos financiamentos. Em alguns produtos básicos da dieta do brasileiro - como o feijão, arroz, milho, hortaliças, mandioca e pequenos animais - chega a ser responsável por $60 \%$ da produção. Por ser diversificada, a agricultura familiar traz benefícios agro, sócio, econômicos e ambientais. Predominantemente no mundo inteiro este é o sistema que ocorre.

A necessidade de pesquisa para atender a crescente demanda da agricultura familiar se torna cada vez mais evidenciada, principalmente na modernização dos sistemas de organização e de gerencia. Outro tema importante é o da verticalização da produção e da comercialização na melhoria da renda, ainda como fonte de renda não se pode esquecer do desenvolvimento de atividades não agrícolas. Para cada região do pais existem situações distintas que tem que ser trabalhadas pela pesquisa e apontadas as alternativas para cada uma dessas regiões. Neste artigo estamos justamente possibilitando a discussão dentro deste tema importante para o Brasil.

Cordeiro, Petersen, e Almeida (1996), colocam uma série de razões pelas quais a agricultura familiar possibilita melhores condições de sustentabilidade, desde que lhe sejam dadas condições:

- A primeira ser uma ocupação econômica que combina a exploração familiar e a organização de profissionais que incorpora equilíbrio econômico, social e ambiental;

- O funcionamento econômico da agricultura familiar não se fundamenta na maximização da rentabilidade do capital e na geração de lucro no curto prazo, e sim nas necessidades das famílias e manutenção do potencial produtivo da terra, percebido como um patrimônio;

- A propriedade familiar é uma unidade de produção e consumo, valoriza a diversidade, os poli-cultivos e criações, distribuídos de forma equilibrada no espaço e no tempo;

- A agricultura familiar mantém uma relação de simbiose com a terra, valoriza as potencialidades do meio implementando suas estratégias de reprodução econômica.

- Do ponto de vista ambiental, favorece maior e melhor distribuição territorial, pelas adaptações das mesmas a unidades ecológicas melhor definidas e homogêneas;

- E por fim, é portadora de grande eficácia coletiva, encoraja e favorece o planejamento, o desenvolvimento local e a gestão coletiva dos recursos naturais, equilibrada e sustentada.

A comunidade Carandá Moita Grande é composta essencialmente de famílias que compõe esse extrato da sociedade. Acredita-se que a através de um planejamento consistente acompanhado de ações realizadas dentro de uma programação coerente que atenda as possibilidades das famílias os resultados de uma melhor gestão certamente serão positivos.

\section{Turismo rural}

No Brasil o turismo rural possui imensuráveis situações favoráveis para o exercício da atividade, como fauna e flora diversificada, culturas, geografia, geologia, cenários alem de vários estilos de vida do homem rural 'caipira', 'sertanista', 'sertanejo', 'gaúcho', peões e outros tantos que fazem de nosso país um grande parque de diversão e distração.

Diariamente a abordagem que propugna as potencialidades e benesses de 'estimular' o desenvolvimento rural via serviços, dentre as quais se destaca fortemente o exame da atividade turística em espaço rural (BALASTRERI, 2000).

\section{Recursos Turísticos}

Para $71,4 \%$ dos entrevistados os recursos turísticos são considerados importantes, $14,3 \%$ consideram essencial, para $10,7 \%$ tanto faz e $3,6 \%$ não souberam responder sobre esse atributo. Apesar de serem considerados importantes, esse recursos ainda não têm sido explorados economicamente.

A paisagem, a cultura regional, a diversidade florística e faunística características do cerrado, as pequenas propriedades possuem potencial para o desenvolvimento 
do turismo rural, significando um meio para aumentar a renda da população rural, valorizando sua propriedade e o seu estilo de vida (Barreto, 2000), podendo, ainda, contribuir com a conservação do patrimônio ambiental.

$\mathrm{O}$ artesanato existente nas comunidades livramentenses ainda não é comercializado e representam, também, uma possibilidade de geração de renda sustentável para os moradores da região.

\section{Cultura Regional}

Quando questionado sobre a importância da cultura, estando inclusos nesse atributo as crenças, estórias, tradições, danças e músicas da região, uma parcela razoável dos entrevistados $(39,29 \%)$ não percebe esses recursos como sendo importantes (Figura 5).

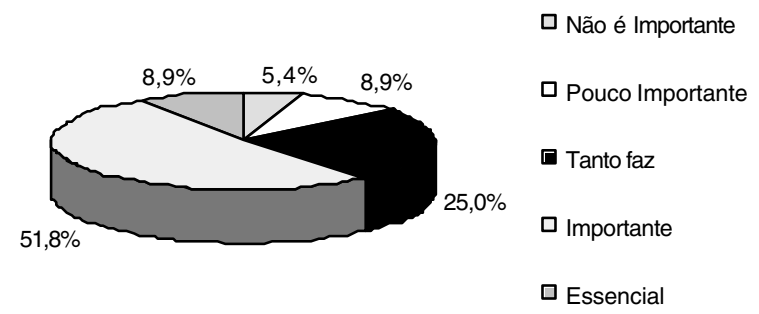

Figura 2. Importância Atribuída a Cultura Regional

Durante as entrevistas foi percebido que o conhecimento tradicional da comunidade em que foram realizadas as entrevistas vem se perdendo ao longo das gerações.

A tradição cultural desempenha um papel importante na determinação do comportamento das pessoas em relação ao ambiente, pois a cultura mantém as populações nos seus ecossistemas, através do conhecimento e informações sobre o meio ambiente e seus recursos, bem como a forma de lidar com eles (DREW, 1986).

Para Toledo (1998), a diversidade cultural deve ser protegida da mesma forma que a diversidade biológica. Para ele, salvaguardar a herança natural do país sem resguardar as culturas que lhe tem dado vida, é reduzir a natureza a algo sem reconhecimento, estático, distante, quase morto.

O folclore em Nossa Senhora do Livramento é bastante forte e deve ser explorado como um atrativo turístico. Composto de tradições religiosas africanas, européias, formando as manifestações próprias da região interessante de ser vsitas.

\section{Considerações}

As alterações ambientais são conseqüências da ocupação do homem, nosso trabalho sugere que a população rural, principalmente a população "Livramentense" utilize o espaço de forma planejada, ordenada e com critérios tendo como atividades principais o Turismo Rural e Agricultura Familiar, opções concreta para o "desenvolvimento local" das comunidades tradicionais e dos assentamentos em Nossa Senhora do Livramento-MT.

O trabalho demonstrou que tem ocorrido pouco intercambio de informação entre as duas estratégias, fator que com certeza demonstra as reais necessidades de estudo e planejamento que possa aportar e melhor desenvolver o rural, distribuindo renda e qualidade de vida das pessoas que ali residem e exercem influência direta na racionalidade do uso dos recursos ambientais.

A comunidade necessita de mais acesso a informação, pois isso garante à população local maior espaço no planejamento e no processo de tomadas de decisão. A educação desempenha um papel poderoso no aumento do envolvimento da população local.

Essas atividades podem estimular um processo que desenvolva a consciência da própria existência em equilíbrio na natureza visando a manutenção da qualidade de vida das atuais e futuras gerações. Esse aprendizado permite que o turista tenha a possibilidade de transformar e renovar seu comportamento cotidiano. O dia á dia urbano com a qual o turista convive gera reflexões sobre a poluição destes grandes centros, manutenção de áreas verdes, destinação e reciclagem de resíduos sólidos melhorando a qualidade de vida. Objetiva-se, assim, a incorporação e tradução destas reflexões na forma de comportamento e posturas no seu ambiente de origem. 


\section{Referências}

ABRAMOWAY, Ricardo. Paradigmas do capitalismo agrário em questão. Campinas: Hucitec/Anpocs/Unicamp, 1992.

ABRAMOVAY, Ricardo. O futuro das regiões rurais. Porto Alegre: Editora da UFRGS, 2003, p. 33.

AIDAR, Antonio Carlos Kfouri e PEROSA JUNIOR, Roberto Mario. Espaços e limites da empresa capitalista na agricultura. Revista de Economia Política. São Paulo: v. 1, n. 2, 1981, p. 17-39.

AULICINO, Madalena Pedroso Algumas Implicações da Exploração Turística dos Recursos Naturais. In: RODRIGUES, Adyr Balastreri (org.) Turismo e Meio Ambiente: Reflexões e Propostas. São Paulo: Hucitec, 1997.

BALASTRERI, Adyr Rodrigues. Turismo Eco-rural. In: Almeida, J.; Froehlich, J. M.; Riedl, M. (orgs.). [s.n.], 2000.

BARRETO, Margarita. Turismo e legado cultural: as possibilidades do planejamento. 2.ed.São Paulo: Papirus, 2000.

BRASIL. Ministério do Turismo. Diretrizes para o Desenvolvimento do Turismo Rural. Disponível em: <http: / / www.mda.gov.br/saf/arquivos / diretrizes.pdf $>$. Acesso em: 06 jul. 2007.

BRASIL, Ministério do Planejamento, Orçamento e Gestão. Instituto Brasileiro de Geografia e Estatística. Disponível em: <www.ibge.gov.br>. Acesso em: 30 ago. 2007.

CORDEIRO, Ângela; PETERSEN, Paulo e ALMEIDA, Silvio Gomes de. Crise sócio-ambiental e conversão ecológica da agricultura brasileira: subsídios à formulação de diretrizes ambientais para o desenvolvimento agrícola. Mimeo. Rio de Janeiro, 1996. 50 p.

DEL GROSSI, Mauro Eduardo. Evolução das ocupações não-agrícolas no meio rural brasileiro: 1981-1995. Tese de
Doutorado. Campinas, IE/Unicamp, 1999.

DREW, David. 1986. Processos Interativos Homem-Meio Ambiente. São Paulo, 206 p.

FERREIRA, Jose Carlos Vicente. Mato Grosso e seus municípios. Cuiabá-MT: Editor Buriti, 2001.

LIKERT, Rensis. A technique for the measurement of attitudes. Arch. Psychol, n. 140, p.1-55. 1932.

LÜDKE, Menga \& ANDRÉ, Marli. Pesquisa em Educação: Abordagens Qualitativas. São Paulo: EPU, 1986.

MAITELLI, G. T. Uma Abordagem Tridimensional de Clima Urbano em Área Tropical Continental: O Exemplo de Cuiabá-MT. Tese (Doutorado) - Faculdade de Filosofia, Letras e Ciências Humanas, Universidade de São Paulo, São Paulo, 1994.

MANN, Suzan A; DICKINSON, James M. Obstacles of the development of a capitalist agriculture. The Journal of Peasant Studies. Londres, v. 5, n. 4, 1978, p. 466-81.

OLIVEIRA, T.M.V. Escalas de mensuração de atitudes: Thurstone, Osgood, Stapel, Likert, Guttman, Alpert. FECAP, v. 2, n. 2, 2001. Disponível em: <www.fecap.br.>. Acesso em: 10 mai. 2007.

PNUD - Programa das Nações Unidas para o Desenvolvimento. Atlas do Desenvolvimento Humano, PNUD. Brasília, 2000.

SEPLAN - Secretaria de Estado de Planejamento e Coordenação Geral. Perfil Sócio Econômico de Mato Grosso. 2004. Disponível em: <http://www.seplan.mt.gov.br/ arquivos/A_8f8f0bd75702c76a957227 ec37c2f65eperfil socioeconomico \%20I.doc> Acesso em: 11 jan. 2008.

SILVA, Dirceu da; BARROS FILHO, Jomar. Ensino de Administração de Empresas: análise de um pré-teste sobre concepções de tecnologia e sociedade de alunos. Revista Álvares Penteado, v. 3, n. 6, p. 119-29. 2001.

TOLEDO, V. M. La diversidad biológica de México. Ciencia y Desarollo, México city, v. XIV, n. 81, p. 17, 1998. 